Cite as: Eck, J., Schoel, C., \& Greifeneder, R. (2016). Coping with or buffering against the negative impact of social exclusion on basic needs: A review of strategies. In P. Riva \& J. Eck (Eds.), Social exclusion: Psychological approaches to understanding and reducing its impact (pp. 227-251). New York, NY: Springer.

\title{
Chapter 11. Coping with or Buffering against the Negative Impact of Social Exclusion on Basic Needs: A Review of Strategies
}

Being socially excluded is a highly aversive experience that entails several negative consequences for the person concerned (for reviews, see Williams, 2007, 2009; Part II in this volume). According to Williams (2009), social exclusion is quickly detected prior to any cognitive appraisal of the situation (but see Rudert \& Greifeneder, 2016, for a different perspective). In the reflexive stage, the four basic human needs for belonging, self-esteem, control, and meaningful existence are threatened, and individuals experience pain and negative affect. In the subsequent reflective stage, the exclusion episode is cognitively appraised and possible coping strategies are activated to restore the threatened needs. In this stage, both dispositional differences, such as social anxiety (Zadro, Boland, \& Richardson, 2006) or an interdependent self-construal (Ren, Wesselmann, \& Williams, 2013), and situational factors, such as the relevance and meaning of the exclusion episode or the underlying motives attributed to it, influence the speed of psychological recovery. With regard to attributions, for instance, Wirth and Williams (2009) have demonstrated that psychological recovery from social exclusion is accelerated when the exclusion episode is attributed to a temporary group membership (e.g., same color of clothes) as compared with a permanent, invariable group membership (e.g., gender). Correspondingly, Goodwin, Williams, and Carter-Sowell (2010) have shown that attributing social exclusion to race (i.e., a permanent group membership) retards recovery.

In addition to the impact of dispositional differences and situational factors on recovery — which mostly fall outside the individual's circle of influence — excluded 
individuals can facilitate recovery by actively coping with the threat social exclusion poses to their basic needs. Adaptive coping strategies to restore basic needs satisfaction are acts useful for reestablishing social connections, such as ingratiating oneself with others by spending money on a product symbolic of group membership (Mead, Baumeister, Stillman, Rawn, \& Vohs, 2011) or creating opportunities for social contact by preferring teamwork over working alone (Maner, DeWall, Baumeister, \& Schaller, 2007). However, there are situations in which potential affiliation partners are absent or the expectation of gaining social acceptance is low. In such situations, social withdrawal or aggressive acts (i.e., acts intended to harm others; Anderson \& Bushman, 2002) become more likely because aggression may help restore a sense of control and being recognized as existing (Williams, 2009). Because social withdrawal and aggression can be detrimental for the individual and the social environment, it is important to make alternative coping strategies available that help excluded individuals restore need satisfaction when the prospect of social acceptance is low. Research on such coping strategies is reviewed in the first part of this chapter.

Coping strategies are utilized after the individual has shown reflexive responses to social exclusion such as need threat and negative affect. By contrast, to buffer the individual against the reflexive responses, strategies have to be utilized prior to or at the onset of the exclusionary event. We introduce a new and promising approach to mitigate or prevent the reflexive responses. This approach may be surprising given the multitude of findings suggesting that reflexive responses to social exclusion are resistant to change. Indeed, research has shown that social exclusion is a threatening and negative experience even if the reasons for the exclusionary event cannot be attributed to the self, for instance, when the exclusion occurs due to technical problems (Eisenberger, Lieberman, \& Williams, 2003) or is based on a pre-programmed script (Zadro, Williams, \& Richardson, 2004). Further, exclusion remains aversive even if the inclusion in the group is not desirable because the inclusion in the group costs money (van Beest, \& Williams, 2006) or the group is an out-group (Smith \& 
Williams, 2004; Williams, Cheung, \& Choi, 2000; Wirth \& Williams, 2009) or a despised group (Gonsalkorale \& Williams, 2007). However, recent findings attest to moderation even in the reflexive stage. We argue that such moderation can be expected when strategies help build up strong psychological resources, such as belonging, self-esteem, control, and meaningfulness, prior to or at the onset of the exclusionary event. Consistent with our psychological resource hypothesis, effective strategies to buffer the reflexive responses to social exclusion share the potential to help build up psychological resources. Research on such buffering strategies is reviewed in the second part of this chapter.

\section{Strategies to Facilitate Psychological Recovery from Social Exclusion}

In this part of the chapter, we review research on strategies that can be used after the exclusionary event to facilitate psychological recovery, especially when no promising affiliation opportunity is available. Such coping strategies help restore need satisfaction and improve mood, and thereby reduce maladaptive reflective responses to social exclusion such as social withdrawal and aggression. The coping strategies we focus on are reminders of social bonds, social surrogates, and turning to religion.

\section{Reminders of Social Bonds}

Many people have photographs of loved ones in their wallets or stored on their smartphones; married people wear wedding rings as a sign of their relationship; and students express their group membership by college sweatshirts. All these things may be regarded as tangible representations of social bonds, which can be used by excluded individuals to regain a sense of belonging (Gardner, Pickett, \& Knowles, 2005). Gardner et al. (2005) reported one study in which participants were asked to relive and write about an experience of either rejection or (nonsocial) failure while having a photograph of either a friend or a liked celebrity on the desk. In accordance with the assumption that photographs of loved ones may be reminders of existing social bonds and thereby boost a sense of belonging, Gardner et al. reported that the mood of participants who relived an exclusionary event remained almost 
unchanged when the photograph of a friend was left on the desk, but dropped significantly when the photograph of a celebrity was within sight. By contrast, the mood of participants who relived a failure was not influenced by the kind of photograph on the desk.

Nowadays, social networking sites such as Facebook have gained importance as a way to communicate with others and to maintain or strengthen social relationships. It therefore seems reasonable to assume that Facebook reminds users of social bonds and helps restore a sense of belonging following social exclusion. Initial evidence for this assumption was recently provided by Knausenberger, Hellmann, and Echterhoff (2015). In their study, Knausenberger et al. used the virtual ball-tossing game Cyberball (Williams et al., 2000) to manipulate social inclusion versus exclusion (for more information on Cyberball and other social exclusion paradigms, see Chapter 2 in this volume). Subsequent to the Cyberball game, participants were exposed to either the Facebook icon (to activate thoughts about Facebook) or the Flash Player icon (control group) in the lower left corner of the screen while completing questionnaires. Because an increased desire for social contact is a typical response to social exclusion (Maner et al., 2007; Williams, 2009), participants indicated their interest in a public activity with friends and in joining a new online social network at the university as dependent variables. As expected, participants exposed to the Flash Player icon showed an increased interest in social contact after exclusion as opposed to inclusion. By contrast, participants' responses in the Facebook condition did not differ significantly between the exclusion and inclusion condition. Activating thoughts about Facebook seemed to be sufficient to regain a sense of belonging. However, this pattern held only for participants who strongly believed that Facebook has relational value or, in other words, those who used Facebook primarily to maintain relationships and social contact with others.

In contrast to the subtle reminder of Facebook used by Knausenberger et al. (2015), Knowles, Haycock, and Shaikh (2015) investigated the moderating effect of actually using Facebook on restoring need satisfaction and aggressive behavior. In one study, social 
inclusion versus exclusion was manipulated by watching a human face that either looked at the participant or averted eye gaze by looking left or right (Wirth, Sacco, Hugenberg, \& Williams, 2010). Participants were then asked to browse through either their photographs on Facebook or pictures of trees on the photo-sharing website Flickr prior to reporting their level of need satisfaction. As was to be expected, need satisfaction was lower following exclusion than inclusion. More important, however, this difference was much smaller when participants had viewed their photographs on Facebook as opposed to the control pictures on Flickr. In one further study, after being included versus excluded in Cyberball, participants were asked to spend a few minutes on Facebook or on a comics website. Aggressive behavior was then measured in the context of a computer game, in which participants were asked to select the volume of aversive white noise another participant would ostensibly be exposed to. Results revealed a tendency for "comic participants" to behave more aggressively following exclusion as compared with inclusion, whereas "Facebook participants" tended to be less aggressive after exclusion than inclusion. Thus, using Facebook following exclusion helped restore need satisfaction, thereby reducing aggressive tendencies often found in response to exclusion when affiliation opportunities are absent.

In addition to tangible or external representations of satisfying social bonds, such as photographs or the Facebook icon, there are intangible or internal representations of social bonds, such as memories and daydreams involving close others (Gardner et al., 2005). The effectiveness of intangible or internal representations of social bonds in regaining a sense of belonging was first tested by Twenge et al. (2007). In one study, participants in the exclusion condition received false feedback that they would live a life alone in the future (Twenge, Baumeister, Tice, \& Stucke, 2001). The exclusion condition was compared with a negativeoutcome, nonsocial control condition in which participants were told that they were likely to be accident prone later in life (misfortune control condition). Immediately after the feedback, participants were asked to think of and write about their favorite family member, their favorite 
celebrity, or their most recent meal. Aggression was then measured with the noise-blasting game described above. Twenge et al. found that participants in the exclusion condition behaved more aggressively than participants in the misfortune control condition when they had written about their recent meal, but aggressive behavior did not differ significantly between conditions when participants had written about their favorite family member or their favorite celebrity. This finding suggests that thinking of both close others and favorite celebrities may help restore a sense of belonging following exclusion. ${ }^{1}$

Twenge et al. (2007) replicated this finding in a second study, in which participants first learned that either all or none of the other participants wanted to work with them on a subsequent task (get-acquainted paradigm; Twenge et al., 2001) and then wrote about either their best friend or their journey to campus. Again, excluded participants behaved more aggressively than included participants when they had written about their journey to campus, but the extent of aggressive behavior did not differ significantly between conditions when participants had thought of their best friend.

Direct empirical evidence that thinking about one's best friend helps restore need satisfaction has been provided by McConnell, Brown, Shoda, Stayton, and Martin (2011). In their study, McConell et al. asked participants to write about either a time when they felt excluded or rejected versus their experiences waking up on the day before the study (control condition). Next, participants wrote an essay about their best friend, their favorite pet, or drew a map of campus. Consistent with the findings of Twenge et al. (2007), excluded versus control participants reported a greater decrease in need satisfaction (between pre- and postmeasurement) when the second task was to draw a map of campus. By contrast, when participants wrote about their best friend or their favorite pet, need satisfaction of excluded and control participants did not differ significantly. Interestingly, writing about one's favorite pet was as effective as writing about one's best friend in restoring basic needs satisfaction following social exclusion. One possible explanation for this finding is the greater inclination 
of excluded individuals to anthropomorphize pets, that is, to treat pets as humanlike and to ascribe humanlike traits related to social support to them (e.g., considerate, sympathetic; Epley, Akalis, Waytz, \& Cacioppo, 2008). Extending these findings, Aydin et al. (2012) demonstrated that bringing a dog into the laboratory after participants had been excluded during the Cyberball game helped them restore feelings of acceptance and a satisfied level of self-esteem and meaningful existence.

Moreover, Knowles and Gardner (2008, Study 2) provided initial evidence that the automatic activation of highly meaningful and cohesive groups (vs. groups of lower meaning and cohesion) facilitates psychological recovery following exclusion. Specifically, excluded participants' self-esteem was greater, the more meaningful and cohesive the groups were they listed in response to the exclusion.

Finally, results of a study by Burson, Crocker, and Mischkowski (2012) suggest that not only reminders of specific social bonds, but also the affirmation of self-transcendent values, that is, values related to harmonious and supportive connections, may foster a sense of belonging. Specifically, Burson et al. manipulated intentional and unintentional exclusion by giving participants false feedback that either nobody wanted to work with them on a subsequent task or others wanted to work with them but, due to an odd number of participants, they were randomly chosen to work alone. Next, one-third of participants was asked to write about a self-transcendent value they had chosen from a list of six values as the most important one to them (e.g., empathy/compassion, being in mutually supportive/caring relationships, trust/openness, and being responsive to the needs of others and one's self); onethird of participants was asked to do the same with self-enhancement values (e.g., appearing intelligent, appearing confident, power/status, and physical attractiveness); and the last third of participants was asked to write about their daily routine (control condition). Given that selfcontrol is typically reduced following social exclusion (Baumeister, DeWall, Ciarocco, \& 
Twenge, 2005), the resistance to the temptation to eat tasty but unhealthy food was measured as dependent variable by the number of cookies eaten in the context of a taste-rating task.

Replicating previous research on self-control, intentionally versus unintentionally excluded participants showed less self-control (i.e., ate more cookies) in the control condition. By contrast, when they had written about a self-transcendent or self-enhancement value, intentionally and unintentionally excluded participants did not differ significantly in the number of cookies eaten. Further, in line with the hypothesis that affirming a selftranscendent value fosters a sense of belonging, participants in the self-transcendent value condition reported feeling more connected, loving, and compassionate than participants in the self-enhancement value or control condition. It remains an open question, however, why also intentionally excluded participants in the self-enhancement value condition recovered faster from social exclusion than control participants, calling for further investigation. Hales, Wesselmann, and Williams (2016) have extended the reported findings by showing that the affirmation of the value of social life and relationships following social exclusion facilitates recovery of basic needs satisfaction. Taken together, reminding oneself of one's social bonds with close others, favorite celebrities, pets, and meaningful, cohesive groups as well as activating social values seem to be effective strategies to facilitate recovery from the negative impact of social exclusion.

\section{Social Surrogates}

If representations of satisfying social bonds are unavailable, excluded individuals may use social surrogates to regain at least an illusion of belonging (Gardner et al., 2005). Social surrogates lead to an experience of belonging in the absence of relational reciprocity. More precisely, although social surrogates do not respond to the individual, they can still satisfy the need to belong because they foster an illusion of feeling connected. The social surrogates discussed in the following are parasocial attachments with favorite television characters, 
comfort food, and nature connectedness. The function of God as a social surrogate is discussed in the section about religion.

Parasocial attachments. The American Time Use Survey (Bureau of Labor Statistics, 2015) revealed that, in 2014, people in the US age 15 and over spent, on average, more than half of their leisure time (53\%) watching television. By way of comparison, they spent, on average, only $12 \%$ of their leisure time socializing and communicating (e.g., visiting with friends or attending social events). People seem to create parasocial attachments, that is, the illusion of face-to-face relationships with media figures (Horton \& Wohl, 1956), especially with their favorite television characters. Moreover, research has shown that the strength of parasocial attachments is positively associated with the dispositional need to belong (Knowles, 2007), but unrelated to feelings of loneliness (McCourt \& Fitzpatrick, 2001; Rubin, Perse, \& Powell, 1985). Twenge et al. (2007) were the first to test the hypothesis that parasocial attachments with media figures help regain a sense of belonging following social exclusion. As reported above, writing about one's favorite celebrity was as effective as writing about one's favorite family member in preventing individuals from aggressive responses to social exclusion.

Knowles (2013) reported a series of studies extending this finding. In three studies, feelings of exclusion were induced by asking participants to recall a time when they felt excluded or rejected and compared with three control conditions, in which feelings of acceptance, failure, or neutral feelings were induced. Subsequently, participants were asked to write about either their favorite television character or a nonsocial control construct (favorite hobby or favorite travel destination). Consistent with previous research, participants who had written about a control construct reported lower self-esteem and greater negative mood and solved less math problems following exclusion as compared with the respective control condition. However, self-esteem, mood, and number of solved math problems did not differ significantly between excluded and control participants when they had written about their 
favorite television character. One of these studies also showed that writing about a favorite television character helped excluded participants regain feelings of belonging and that these feelings of belonging accounted for the effect of the writing task on excluded participants' mood. Knowles reported one further study in which social exclusion versus inclusion was manipulated via Cyberball prior to exposing participants to images of either their own or another participant's favorite television character. Participants who saw images of another participant's favorite television character described their in-groups as significantly more meaningful and cohesive than their out-groups following exclusion versus inclusion. By contrast, participants reminded of their own favorite television character described both groups comparably meaningful and cohesive irrespective of whether they had been excluded or included. Presumably, these participants no longer needed to utilize self-protective cognitions (i.e., in-group favoritism) to bolster their sense of belonging because their favorite television character had already helped them recover.

Derrick, Gabriel, and Hugenberg (2009) demonstrated that participants faced with a belongingness threat (i.e., those who recalled a fight with a close other) wrote significantly longer and more words about their favored television program than control participants who had listed objects in their residence. By contrast, threatened and control participants did not differ significantly in the time spent and the number of words when writing about watching TV in general. Moreover, most essays described a social program (e.g., sitcoms or dramas) irrespective of whether the program was favored or not. These results indicate that individuals rely on the parasocial attachments provided by their favorite television program, rather than relying on any media figure, to cope with threats to their sense of belonging. In a further study, Derrick et al. employed the same tasks but held the time constant that participants spent on writing about a favorite television program versus whatever was on television. Results showed that threatened participants reported lower self-esteem and greater negative affect than control participants when they were reminded of any television program. However, in 
accord with the findings reported by Knowles (2013), threatened and control participants' self-esteem and negative affect did not differ significantly when they were reminded of their favorite television program. Altogether, relying on parasocial attachments with favorite television characters seems to facilitate recovery after having been faced with a social threat.

Comfort food. Social surrogates do not necessarily have to be human, as findings on comfort food illustrate. The term comfort food refers to all kinds of food whose intake is subjectively experienced as satisfying. Thus, individuals differ in their preferences for comfort foods. Moreover, comfort food is often eaten to alleviate negative affective states (e.g., Dube, Lebel, \& Lu, 2005; Evers, Stok, \& de Ridder, 2010). Multiple reasons are conceivable why a specific food is experienced as comfort food. One reason proposed by Troisi and Gabriel (2011) is especially relevant with regard to the assumption that comfort food can serve as a social surrogate. According to Troisi and Gabriel, comfort foods are food items that were often initially eaten in the presence of close others. They further postulated that the perceptual experience of eating these food items was therefore encoded along with the abstract concept of social comfort. As a result, eating these food items, or even thinking about eating them, is assumed to automatically activate the associated concept, which enables individuals to re-experience the social comfort that was initially encoded along with the food items.

As hypothesized, Troisi and Gabriel (2011) have found that eating comfort food activates the concept of social comfort, which was measured by the number of completed words related to good relationships (e.g., like, include) in a word-completion task. Moreover, Troisi and Gabriel asked participants to either write about a fight with a close other (inducing a threat to one's belonging) or list items in their residence (control condition) and then to write about the experience of either eating a comfort food or trying new food. Participants who recalled a fight with a close other reported significantly less feelings of disconnection when they had written about comfort food as compared with new food. This finding, however, 
was limited to participants with a secure attachment style, that is, those who experience social comfort in the presence of relationship partners to a great degree and therefore are more likely to associate comfort food with social comfort. The feelings of participants with an insecure attachment style and participants in the control condition were not influenced by writing about comfort or new food. Considered together, eating comfort food helps alleviate feelings of social disconnection following a social threat, given that the individual has strongly positive cognitive associations with relationships as it applies to securely attached individuals.

Nature connectedness. Nature connectedness, that is, an "individual's experiential sense of oneness with the natural world" (Mayer \& Frantz, 2004, p. 504), seems to be another promising social surrogate candidate. A body of research has shown that emotional, physiological, and attentional restoration is enhanced in natural environments (e.g., Hartig, Evan, Jamner, Davis, \& Gärling, 2003; Ulrich et al., 1991). Moreover, nature connectedness has been found to be positively associated with ratings of psychological well-being (e.g., ratings of self-acceptance, purpose in life, and environmental mastery) and social well-being (e.g., ratings of social acceptance, social actualization, and social integration) (Howell, Dupko, Passmore, \& Buro, 2011; Howell, Passmore, \& Buro, 2013). Given that nature connectedness increases psychological and social well-being, one may expect that socially excluded individuals seek nature connectedness.

Poon, Teng, Chow, and Chen (2015) have provided first empirical evidence that social exclusion increases the desire for nature connectedness. In two studies, Poon et al. manipulated social exclusion versus inclusion or a negative, non-social experience by means of an imagined scenario or the recall of a past experience of social exclusion versus physical pain. Nature connectedness was measured by asking participants how likely they were to engage in nature-related activities (e.g., lying on grassland, planting flowers) or the connectedness to nature scale (e.g., "I want to feel a sense of oneness with the natural environment around me;" Mayer \& Frantz, 2004). Across both studies, Poon et al. found that 
social exclusion resulted in a greater desire to connect to nature as compared with social inclusion or the negative, non-social control condition. Moreover, socially excluded participants indicated a greater willingness to engage in sustainable behavior (e.g., recycling, taking shorter showers) than control participants, and their increased desire to connect to nature accounted for this effect. Thus, in addition to serving as a social surrogate, nature connectedness may help individuals cope with social exclusion by promoting behavior that fosters social acceptance.

\section{Religion}

A recent poll of 63,898 people from 65 countries across the globe conducted by WIN/Gallup International (2015) revealed that $63 \%$ of people say they are religious. Wesselmann and Williams (2010) suggested that having to cope with social exclusion is one reason that motivates people to turn to religion because religion has the potential to fulfill the four basic needs threatened by social exclusion. First, religion can fulfill the need for belonging by reminding people of their relationships with other members of their religious community, thereby fostering a sense of social identity and increasing confidence in having an opportunity for frequent and personal social contact. Moreover, incorporeal beings, such as angels, spirits, and God in particular, can serve the function of a social surrogate (Kirkpatrick, 1998). Second, religion can fulfill the need for self-esteem by reminding people of an allloving God and the uniqueness ascribed to each individual. Third, religion can fulfill the need for control by reminding people of the belief that personal outcomes (including the circumstances of afterlife) are influenced by the extent to which an individual's behavior and choices comply with prescribed rules of the respective religious community. In addition, religious people believe that they are able to exert influence by including requests from God in their prayers. Correspondingly, prayer is associated with greater self-control (DeWall et al., 2014; Friese \& Wänke, 2014). Fourth, religion can fulfill the need for meaningful existence by offering an answer to the question about the meaning of life. Kashdan and Nezlek (2012) 
have shown that present daily spirituality predicts next day's meaning in life. Also, people's religious beliefs have been found to be stronger when they are coping with existential anxiety (Norenzayan \& Hansen, 2006). In conclusion, religion has the potential to restore the basic needs threatened by social exclusion.

In accord with Wesselmann and Williams' (2010) assumptions, research has demonstrated that social exclusion (vs. inclusion or a control condition) results in greater selfreported religiosity, greater intention to show private religious behavior (e.g., practicing private religious rituals, praying for oneself, and talking to God), and a stronger belief in the existence of supernatural agents or associated forces (e.g., God, angels, the Devil, ghosts, miracles, and curses) (Aydin, Fischer, \& Frey, 2010; Epley, et al., 2008). Likewise, Laurin, Schumann, and Holmes (2014) have found that inducing relationship concerns results in greater self-reported closeness to God, greater willingness to respond constructively to God's hurtful behavior, and greater interest in a God exercise which includes having a private conversation with God. However, in two out of three studies, the effects were limited to individuals high in self-esteem (i.e., those who expect to be socially accepted by others to a great degree). The reported findings suggest that socially excluded individuals turn to religion to cope with threatened needs. But is this coping strategy effective?

In one study of Aydin et al. (2010, Study 5), participants were asked to write about their attitude toward either religiousness and faith or environment protection after a scenariobased manipulation of social exclusion versus inclusion. Aggression was measured by asking participants to determine the duration another participant would have to keep his or her hand in ice water (although no participant had to do this task in fact). Participants who had been reminded of environment protection responded more aggressively to exclusion than inclusion. By contrast, included and excluded participants who had been reminded of religiousness did not differ significantly in their aggression, supporting the assumption that religion can contribute to restoring need satisfaction. 
Furthermore, Hales et al. (2016, Study 3) investigated the effects of prayer, affirmation of the value of social life and relationships, and distraction on recovery from social exclusion. All participants were excluded during the Cyberball game prior to completing one of the following tasks: (1) saying a prayer to oneself and writing down the content of the prayer, (2) thinking and writing about why social life and relationships are important to oneself, (3) describing in detail the last meal one ate (distraction task), or (4) writing about one's momentary thoughts (control condition). Need satisfaction as well as positive and negative affect were measured twice: once directly after the Cyberball game and once after the intervention. All three interventions resulted in greater recovery of basic needs satisfaction as compared with the control condition. Moreover, the three interventions did not differ significantly in the amount of recovery. However, the mechanisms through which they influence recovery seem to differ. Reductions in rumination about the exclusionary event accounted only (in part) for recovery in the distraction condition. As previously described, one may assume that social affirmation serves as a reminder of social connectedness and prayer - as a way to practice one's religion-reminds people of their religious community and connection to God, and provides them a sense of uniqueness, self-control, and meaning in life. Finally, Hales et al. found that saying a prayer resulted in greater recovery for people with high as opposed to low religious commitment to God. Thus, turning to religion seems to be an effective strategy to cope with the negative consequences of social exclusion but more so for believers than nonbelievers.

\section{Strategies to Buffer the Reflexive Responses to Social Exclusion}

To date, very few strategies have been identified that mitigate the strong, immediate negative impact of social exclusion on the basic needs and affect, jointly referred to as reflexive responses to social exclusion. The coping strategies discussed in the first part of this chapter are utilized after an exclusionary event to facilitate psychological recovery. By contrast, strategies to buffer reflexive responses to social exclusion have to be utilized prior to 
or at the onset of an exclusionary event. We therefore postulate that strategies helping build up strong psychological resources, such as belonging, self-esteem, control, and meaningful existence, may prove to be effective buffers against the reflexive responses to social exclusion. We henceforth refer to this account as the psychological resource hypothesis and review supporting evidence that investigated the role of social companionship, belonging to a majority, money, and powerful positions.

\section{Social Companionship}

According to the old saying "Misery loves company," one may assume that sharing the negative experience of social exclusion with another person reduces its impact on the excluded individual's psychological well-being. But do all kinds of company (e.g., stranger, close other) serve this purpose? In two studies, van Beest, Carter-Sowell, van Dijk, and Williams (2012) found that both participants who were in the company of a stranger while they played Cyberball and participants who played the game alone reported lower levels of need satisfaction following exclusion as compared with inclusion. Thus, it seems that strangers do not provide the psychological resources that help defend the individual's basic needs against social exclusion.

By contrast, the company of a close other should have the potential to boost one's sense of belonging, self-esteem, control, and meaningfulness. However, it is likely that the benefit of being in the company of a close other is limited to people with high trait selfesteem. The sociometer theory (Leary \& Baumeister, 2000; Leary, Tambor, Terdal, \& Downs, 1995) postulates that the self-esteem system mirrors one's standing with others. More precisely, the level of trait self-esteem reflects the extent to which the individual generally perceives others to regard their relationship as close, valuable, and important.

Correspondingly, people with high trait self-esteem should feel close to others, they should feel valued and supported by others, thereby increasing their perceived ability to exert influence on their social environment, and they should feel important. By contrast, people 
with low trait self-esteem should feel neither very close to others nor valued and important, which results in a tendency to expect exclusion by others (Leary \& Baumeister, 2000; Leary et al., 1995). Therefore, close others, such as friends and partners, are unlikely to boost the sense of belonging, self-esteem, control, and meaningfulness in individuals with low trait selfesteem. In accord with this, individuals with high trait self-esteem have been found to show an increased desire for social contact with close others when experiencing a threat in a domain of high versus low relevance to their self-worth, whereas individuals with low trait selfesteem showed a decreased desire (Park \& Maner, 2009).

Teng and Chen (2012) empirically tested the moderating effect of different kinds of company (stranger vs. close other) on the relationship between social exclusion and need satisfaction of individuals high or low in trait self-esteem. Replicating the findings of van Beest et al. (2012), they found that participants who were in the company of a stranger while they played Cyberball reported lower levels of need satisfaction following exclusion as compared with inclusion irrespective of their level of trait self-esteem. However, participants' level of need satisfaction did not differ significantly between the exclusion and inclusion condition when they were in the company of a close other and had high (vs. low) trait selfesteem. Thus, not companionship in general but having a close other at one's side during an exclusionary event can buffer social exclusion's immediate impact on the basic needs given that the excluded individual has high trait self-esteem.

Research on strategies to cope with the negative consequences of social exclusion has revealed that reminders of a social bond with a significant other following social exclusion help recover basic needs satisfaction irrespective of trait self-esteem (McConnell et al., 2011; Twenge et al., 2007). If a social bond is merely remembered, people with low trait self-esteem do not have to worry about being excluded by their significant other. Building on these research findings, one may expect that thinking of a significant other prior to or at the onset of an exclusionary episode bolsters one's sense of belonging, thereby reducing the susceptibility 
to threats from social exclusion. Our findings from two recent studies (Eck, Schoel, \& Greifeneder, 2016a), however, challenge this supposition.

In a first study, we investigated whether people who are in a relationship would differ from single persons in their immediate, reflexive responses to social exclusion as a function of relationship status activation. In all conditions, need satisfaction was lower following exclusion as compared with inclusion during the Cyberball game. However, excluded participants who thought about their relationships prior to the Cyberball game reported significantly less need satisfaction than excluded participants who thought about their life as single persons and excluded control participants (i.e., those who indicated their relationship status at the end of the study). These results suggest that reminders of one's relationship prior to being excluded enhance susceptibility to threats from social exclusion. To further substantiate these findings, in a second study, we directly tested the effects of the concepts activated by the respective relationship status, namely feeling connected to another person (activated in people in a relationship) and feeling independent from others or alone (activated in single persons). Replicating the findings of the first study, excluded participants who felt connected to another person reported significantly less need satisfaction than excluded participants who felt independent from others. Moreover, need satisfaction of excluded participants who felt alone fell in between these two conditions.

Taken together, the results of these two studies suggest that a reminder of a social bond (vs. a reminder of one's independence or a control condition without reminder) prior to the exclusionary event even lowers need satisfaction to a greater extent. Presumably, being reminded of one significant social connection (or a lack of social connections as it applies to people feeling alone) may highlight the importance of belonging for well-being, which, in turn, intensifies the need threat that is experienced in response to social exclusion.

Interestingly, Hermann, Skulborstad, and Wirth (2013) have found that thinking of a person who unconditionally accepts one helps buffer the immediate effect of social exclusion 
on the basic needs to some extent for securely attached people. Specifically, in their study, participants were asked to write either about a person who clearly and unconditionally accepts them (unconditional acceptance condition) or about a coworker or classmate whom they did not know well (control condition) prior to playing Cyberball. In both essay conditions, excluded participants reported significantly less need satisfaction than included participants. However, need satisfaction of excluded participants was significantly greater in the unconditional acceptance condition as compared with the control condition when they had a secure attachment style. Nevertheless, participants reported that it was relatively difficult for them to identify a person who unconditionally accepts them.

Considered together, being in the company of a close other, but not a stranger, helps reduce reflexive responses to social exclusion only if the excluded individual has high trait self-esteem. By contrast, merely being reminded of a social bond with a close other does not buffer social exclusion effects on basic needs but even reinforce them. However, basic needs of securely attached individuals can be defended against the impact of social exclusion to some extent by thinking in particular of a social bond in which they feel unconditionally accepted.

\section{Belonging to a Majority}

Social contexts are characterized by groups holding the majority or minority position toward each other (Sachdev \& Bourhis, 1991). More often than not, belonging to the majority group is perceived as good whereas belonging to the minority group is perceived as bad (Moscovici, 1980). As group memberships are part of one's social identity, the status of a group as a majority or minority influences their members' thoughts, feelings, and behaviors to a great extent. It therefore seems reasonable to assume that perceiving oneself as a member of a majority group may help build up psychological resources to buffer the negative impact of social exclusion on the basic needs. More precisely, majority groups provide the opportunity to feel connected to many people, can contribute to a high self-esteem of their members due to 
the positive attributes associated with majorities (Kruglanski \& Mackie, 1990; Moscovici, 1980; Sachdev \& Bourhis, 1984, 1991), and give members a feeling of being in control over their social environment as well as being recognized as existing because of the high power ascribed to majorities (Keltner, Gruenfeld, \& Anderson, 2003; Lücken \& Simon, 2005).

The moderating effect of group membership, however, is more likely to occur among individuals with a generally strong desire for acceptance and belonging (i.e., those with a high dispositional need to belong). Individuals with a high (vs. low) dispositional need to belong place greater importance on their social identity, including their interpersonal relationships and social groups (Leary, Kelly, Cottrell, \& Schreindorfer, 2013). We therefore tested in two studies whether perceiving oneself as a member of a majority group reduces the immediate effect of social exclusion on the basic needs according to one's dispositional need to belong (Eck, Schoel, and Greifeneder, 2016b).

In the first study, group membership (majority vs. minority vs. unknown group size) was manipulated via feedback on a perception task prior to experiencing social inclusion versus exclusion in a scenario. Supporting our hypothesis, participants high in the need to belong who belonged to the minority group or the group of unknown size showed less need satisfaction following exclusion as compared with inclusion. Basic needs satisfaction of participants high in the need to belong, however, did not differ significantly between the inclusion and exclusion condition when they belonged to the majority group. Unexpectedly, participants low in the need to belong showed no social exclusion effect in all three group conditions. Presumably, inducing social exclusion by a scenario was not sufficiently strong to affect individuals with a relatively weak desire for acceptance and belonging.

In a second study, we used the same procedure as in the first study but manipulated social inclusion versus exclusion using Cyberball and replaced the minority group with a control condition, in which participants received no feedback on the perception task (no group condition). Again, basic needs satisfaction of participants high in the need to belong was 
lower following exclusion as compared with inclusion in the unknown group size and no group condition but not in the majority group condition. By contrast, participants low in the need to belong showed a social exclusion effect irrespective of group membership. The comparison of the unknown group size and majority group conditions with the no group condition substantiates the assumption that not just any group but majority groups in particular possess the potential to provide their members with the necessary psychological resources to mitigate the impact of social exclusion given that individuals have a high dispositional need to belong.

\section{Money}

To survive, people have to afford means to meet their physiological needs (e.g., water, food) and their need for security (e.g., a dwelling place). Moreover, having money allows materialistic consumption that may serve to fulfill further basic needs. In line with this, researchers have argued that money or just the mere thought of having money boosts feelings of strength, efficacy, and confidence with regard to one's ability to maintain need satisfaction, and enhances feelings of self-sufficiency (Vohs, Mead, Goode, 2006; Zhou \& Gao, 2008; Zhou, Vohs, \& Baumeister, 2009). More precisely, researchers have suggested that people rely on materialistic consumption to counter peer rejection (Banerjee \& Dittmar, 2008), to deal with doubts about their competence and self-worth (Chang \& Arkin, 2002), to compensate for a lack of control (Christopher, Saliba, \& Deadmarsh, 2009), and to establish meaning in life when confronted with death anxiety (Arndt, Solomon, Kasser, \& Sheldon, 2004). Thus, materialistic consumption can be expected to foster a sense of belonging, selfesteem, control, and meaningfulness. However, in modern times people need money to be able to invest in material goods. Therefore, one may argue that money helps maintain need satisfaction by enabling materialistic consumption. Further, as maintaining need satisfaction via materialistic consumption is not reliant on others, people having money are likely to feel 
self-sufficient and especially strong, efficient, and confident with regard to their ability to meet their needs.

Initial evidence for the assumption that activating the concept of money buffers the effects of social exclusion has been provided by Zhou et al. (2009). Before playing Cyberball, participants were asked to count out either $80 \$ 100$ bills (activating the money concept) or 80 pieces of paper. As expected, excluded participants who counted money as opposed to paper reported higher self-esteem and feelings of strength. By contrast, counting money versus paper had no significant effect on the self-esteem and feelings of strength of included participants. Moreover, feelings of strength and self-esteem were positively associated. In another study, participants were asked to either list their monetary expenditures for the past 30 days or write about the weather condition over the past 30 days prior to playing Cyberball. Zhou et al. found that reflecting on money loss as opposed to the weather reduced self-esteem in both the exclusion and inclusion condition, but the decrease in self-esteem was significantly larger following exclusion. Participants who reflected on money loss also reported feeling less strong than those who reflected on the weather, and feelings of strength and self-esteem were again positively related. Thus, thinking of having money, but not thinking of money loss, increases feelings of strength and buffers against the decrease in selfesteem when being excluded.

Lelieveld, Gunther Moor, Crone, Karremans, and van Beest (2013) investigated the buffering effect of money on all four basic needs. In three studies, all participants played Cyberball but half of them were financially compensated for being excluded by receiving 50 Euro cent for each ball that was not thrown to them. Across all studies, participants reported lower need satisfaction following exclusion as compared with inclusion, but excluded participants who were financially compensated reported higher need satisfaction than excluded participants who were not compensated. These findings underpin the hypothesis that money has the potential to buffer the threat social exclusion poses to the basic needs. 


\section{Powerful Positions}

Power is a central force in social relationships (Galinsky, Rus, \& Lammers, 2011). Powerful positions are characterized by the capacity to exert influence on others through having control over resources (Keltner et al., 2003). Accordingly, being in a powerful position is quite likely to boost one's sense of control. Power holder's sense of control may even be so strong that they perceive illusory control over random outcomes (Fast, Gruenfeld, Sivanathan, \& Galinsky, 2009). Moreover, powerful positions are often linked with greater positive affect (e.g., Anderson \& Berdahl, 2002; Berdahl \& Martorana, 2006; Langner \& Keltner, 2008), which may counteract the increase of negative affect following social exclusion. Finally, being in a powerful position may boost one's sense of self-esteem. However, the link between powerful positions and higher self-esteem seems to be indirect via perceived control and affect (Fast et al., 2009; Wojciszke \& Struzynska-Kujalowicz, 2007).

Kuehn, Chen, \& Gordon (2015) examined the moderating effect of social power on negative emotions and self-esteem. They conducted a two-week diary study to investigate the relationship between relative power in a romantic relationship and negative emotions felt in response to perceived partner hostility as a proxy of rejection. The study results have shown that on days on which participants perceived their partners as accepting, power was not associated with negative emotions. By contrast, on days on which participants perceived their partners as rejecting, higher power was associated with less negative emotions.

In a second study, Kuehn et al. (2015) induced high versus low power experimentally by assigning participants to the role of a boss versus employee in a task on solving brainteasers. All materials from the partner ostensibly assigned to the other role were prepared in advance. Social rejection versus acceptance was then manipulated by asking participants to complete a questionnaire about themselves that ostensibly served to exchange information between participants, and to indicate on a scale how much they wanted to work with the other participant on a task due to the exchanged information. Subsequently, they received false 
feedback by the other participant that was either mildly rejecting (i.e., the mean rating was slightly below the scale midpoint) or mildly accepting (i.e., the mean rating was slightly above the scale midpoint). As expected, participants in a low-power role reported more negative emotions and lower self-esteem when they were rejected as opposed to accepted, whereas negative emotions and self-esteem of participants in a high-power role did not differ significantly between the rejection and acceptance feedback.

To further substantiate these findings, in their last study, Kuehn et al. (2015) included a control condition in which the participant and the rejector had equal power. To this end, participants were asked to imagine that they held either a high-power or low-power position at a company. They were further asked to imagine that they were not invited to a post-work happy hour they typically enjoyed going to. Finally, they were told that the co-worker who planned the happy hour (i.e., the rejector) held either a high-power or low-power position. Supporting the assumption that a powerful position may attenuate the effect of social exclusion on self-esteem, participants in the high-power position reported higher self-esteem than both those in the low-power position and those in the equal-power condition, who did not differ significantly from each other in their level of self-esteem.

We manipulated power in a more subtle way utilizing Cyberball (Schoel, Eck, \& Greifeneder, 2014). In the standard Cyberball paradigm, the characters representing the two other (preprogrammed) players are positioned on top of an upside-down triangle, whereas the character representing the participant is positioned at the bottom. This spatial arrangement is reasonable because people perceive things positioned lower in their visual field as closer than things positioned higher; and they typically visualize themselves in close spatial proximity, whereas others are visualized as farther away (Goldstein, 2007). However, the position of the characters is not just vertically higher versus lower but also psychologically. People often use the spatial dimension to express powerful versus powerless positions. Specifically, people associate things at the top with high power and things at the bottom with low power (for 
empirical evidence, see, e.g., Giessner \& Schubert, 2007; Schoel, Zimmer, \& Stahlberg, 2015; Schubert, 2005). Following this line of thought, we flipped the standard Cyberball arrangement vertically, so that the character depicting the participant was positioned above the characters depicting the two supposed other players, and compared it with the standard arrangement. In addition to affect and all four basic needs, we measured aggression toward the other players to show that buffering the impact of social exclusion on affect and the need for control reduces aggressive acts of retaliation. Based on the hot sauce allocation task (Lieberman, Solomon, Greenberg, \& McGregor, 1999; see also Warburton, Cairns, \& Williams, 2006), aggression was measured by asking participants to imagine ordering lunch for the people involved in the Cyberball game and to choose how spicy they would order the meals. As the others were described as not tolerating very spicy meals, choosing more spicy meals indicated a stronger intention to harm others.

In line with our hypotheses, the impact of exclusion (vs. inclusion) on affect and the need for control was greater for participants positioned below the other players (i.e., in a powerless position) as compared with those positioned above (i.e., in a powerful position). Moreover, we found that participants in a powerless position behaved more aggressively following exclusion as opposed to inclusion, whereas the aggressive behavior of participants in a powerful position did not differ significantly between the exclusion and inclusion condition. Finally, the reduced aggression of participants in a powerful position toward the excluding players could in part be attributed to their lower level of negative affect and higher level of perceived control as compared with participants in a powerless position. Please note that these findings do not challenge the standard Cyberball paradigm as being "below" and being excluded likely accompany each other more often than not. Not to mention the fact that research findings based on Cyberball closely resemble those based on other social exclusion paradigms. However, investigations of power should take into account that power is confounded with spatial position. 
To summarize the empirical evidence on the buffering effect of power, being or visualizing oneself in a powerful position may reduce the effect of exclusion on the need for self-esteem and control as well as on affect. It thereby also helps prevent aggressive acts of retaliation against the perpetrators of the exclusion episode.

\section{Discussion}

The research reviewed in this chapter focused on responses to short-term social exclusion. If individuals are excluded for prolonged periods of time, in which they continuously fail to restore need satisfaction or to end the exclusion, it is likely that they will enter a stage of resignation. Individuals in the resignation stage likely resign themselves to their low need satisfaction, which may cause feelings of alienation, depression, helplessness, and unworthiness (Williams, 2007, 2009). Although this is speculative, it is reasonable to assume that the reviewed coping strategies can help delay entering the resignation stage and thereby increase the chance of finding new affiliation opportunities, which, in turn, protect the individual from resignation. Presumably, the coping strategies may also help individuals in the resignation stage to feel temporarily better. However, because of the importance of social relationships for health and well-being (Baumeister \& Leary, 1995), the only effective way to end the resignation stage seems to be actual social re-inclusion.

With regard to buffering strategies, one may argue that buffering the reflexive responses to social exclusion reduces the individual's chance to recognize situations that require behavioral changes to regain social acceptance. Again, it is important to note that the discussed buffering strategies have been found to attenuate reflexive responses to short-term social exclusion. It is quite likely that the built up psychological resources become gradually depleted when the individual is exposed to prolonged exclusion episodes. Thus, the buffering strategies help prevent decreases in need satisfaction when social exclusion is unintended and meaningless (e.g., when your co-workers did not ask you for joining them for lunch because they thought you were out of office), but do not shut down the individual's ability to detect 
prolonged, meaningful social exclusion (e.g., when friends do not inform you about group activities repeatedly because they do not want you to join them).

\section{Conclusion}

In this chapter, we gave an overview of research on strategies that help cope with or buffer against the negative psychological consequences of social exclusion. Coping strategies are utilized after the individual has shown reflexive responses to social exclusion (e.g., need threat, negative affect) and aim at facilitating psychological recovery. Specifically, coping strategies help prevent maladaptive reflective responses to social exclusion such as social withdrawal and aggression by helping restore basic needs satisfaction and improve mood. As social withdrawal and aggression are more likely to occur in response to social exclusion when no affiliation opportunity is available or the prospect of social acceptance is low, we focused on coping strategies that can be utilized in such situations, namely reminders of social bonds, social surrogates, and turning to religion.

In contrast to coping strategies, buffering strategies are utilized prior to or at the onset of an exclusionary episode and are intended to mitigate or prevent the reflexive responses to social exclusion. Until recently, research findings suggested that reflexive responses to social exclusion are resistant to change. In this chapter, however, we provided evidence for our psychological resource hypothesis that building up strong psychological resources, such as belonging, self-esteem, control, and meaningfulness, prior to or at the onset of an exclusionary episode has a buffering effect. The buffering strategies discussed in this chapter were social companionship during the exclusionary event, belonging to a majority, thinking about money, and visualizing oneself in a powerful position. Taken together, the psychological resource hypothesis seems to be a promising approach for future research to further fill the gap of effective buffering strategies. 


\section{References}

Anderson, C., \& Berdahl, J. L. (2002). The experience of power: Examining the effects of power on approach and inhibition tendencies. Journal of Personality and Social Psychology, 83, 1362-1377.

Anderson, C. A., \& Bushman, B. J. (2002). Human aggression. Annual Review of Psychology, $53,27-51$.

Arndt, J., Solomon, S., Kasser, T., \& Sheldon, K. M. (2004). The urge to splurge: A terror management account of materialism and consumer behavior. Journal of Consumer Psychology, 14, 198-212.

Aydin, N., Fischer, P., \& Frey, D. (2010). The effects of social exclusion on religiousness. Personality and Social Psychology Bulletin, 36, 742-753.

Aydin, N., Krueger, J., Fischer, J., Hahn, D., Frey, D., Kastenmüller, A., \& Fischer, P. (2012). A man's best friend - how the presence of a dog decreases mental distress after social exclusion. Journal of Experimental Social Psychology, 48, 446-449.

Banerjee, R., \& Dittmar, H. (2008). Individual differences in children's materialism: The role of peer relations. Personality and Social Psychology Bulletin, 34, 17-31.

Baumeister, R. F., DeWall, C. N., Ciarocco, N. J., \& Twenge, J. M. (2005). Social exclusion impairs self-regulation. Journal of Personality and Social Psychology, 88, 589-604.

Baumeister, R. F., \& Leary, M. R. (1995). The need to belong: Desire for interpersonal attachments as a fundamental human motivation. Psychological Bulletin, 117, 497529.

Berdahl, J. L., \& Martorana, P. (2006). Effects of power on emotion and expression during a controversial group discussion. European Journal of Social Psychology: Special Issue on Social Power, 36, 497-510.

Bureau of Labor Statistics (2015). The American Time Use Survey. Retrieved from http://www.bls.gov/news.release/archives/atus_06242015.htm 
Burson, A., Crocker, J., \& Mischkowski, D. (2012). Two types of value affirmation: Implications for self-control following social exclusion. Social Psychological and Personality Science, 3, 510-516.

Chang, L., \& Arkin, R. M. (2002). Materialism as an attempt to cope with uncertainty. Psychology and Marketing, 19, 389-406.

Christopher, A. N., Saliba, L., \& Deadmarsh, E. J. (2009). Materialism and well-being: The mediating effect of locus of control. Personality and Individual Differences, 46, 682686.

Derrick, J. L., Gabriel, S., \& Hugenberg, K. J. (2009). Social surrogacy: How favored television programs provide the experience of belonging. Journal of Experimental Social Psychology, 45, 352-362.

DeWall, C. N., Pond, R. J., Carter, E. C., McCullough, M. E., Lambert, N. M., Fincham, F. D., \& Nezlek, J. B. (2014). Explaining the relationship between religiousness and substance use: Self-control matters. Journal of Personality and Social Psychology, $107,339-351$.

Dube, L., LeBel, J. L., \& Lu, J. (2005). Affect asymmetry and comfort food consumption. Physiology \& Behavior, 86, 559-567.

Eck, J., Schoel, C., \& Greifeneder, R. (2016a). All you need is love? Feeling connected results in more negative reactions to ostracism than feeling independent. Manuscript in preparation.

Eck, J., Schoel, C., \& Greifeneder, R. (2016b). Belonging to a majority reduces the immediate need threat from ostracism in individuals with a high need to belong. Manuscript under revision.

Eisenberger, N. I., Lieberman, M. D., \& Williams, K. D. (2003). Does rejection hurt? An fMRI study of social exclusion. Science, 302, 290-292. 
Epley, N., Akalis, S., Waytz, A., \& Cacioppo, J. T. (2008). Creating social connection through inferential reproduction: Loneliness and perceived agency in gadgets, gods, and greyhounds. Psychological Science, 19, 114-120.

Evers, C., Stok, M. F., \& de Ridder, D. T. (2010). Feeling your feelings: Emotion regulation strategies and emotional eating. Personality and Social Psychology Bulletin, 36, 792804.

Fast, N. J., Gruenfeld, D. H., Sivanathan, N., \& Galinsky, A. D. (2009). Illusory control: A generative force behind power's far-reaching effects. Psychological Science, 20, 502508.

Friese, M. \& Wänke, M. (2014). Personal prayer buffers self-control depletion. Journal of Experimental Social Psychology, 51, 56-59.

Galinsky, A. D., Rus, D., \& Lammers, J. (2011). Power: A central force governing psychological, social, and organizational life. In D. De Cremer, R. van Dick, \& J. K. Murnighan (Eds.), Social psychology and organizations (pp. 17-38). New York, NY: Routledge/Taylor \& Francis Group.

Gardner, W. L., Pickett, C. L., \& Knowles, M. L. (2005). Social "snacking" and social "shielding": The satisfaction of belonging needs through the use of social symbols and the social self. In K. Williams, J. Forgas, and W. von Hippel (Eds.), The social outcast: Ostracism, social exclusion, rejection, and bullying (pp. 227-241). New York, NY: Psychology Press.

Giessner, S. R., \& Schubert, T. (2007). High in the hierarchy: How vertical location and judgments of leaders' power are interrelated. Organizational Behavior and Human Decision Processes, 104, 30-44.

Goldstein, E. B. (2007). Sensation and perception (7th ed.). Belmont, CA: WadsworthThomson Learning. 
Gonsalkorale, K., \& Williams, K. D. (2007). The KKK won't let me play: Ostracism even by a despised outgroup hurts. European Journal of Social Psychology, 37, 1176-1186.

Goodwin, S. A., Williams, K. D., \& Carter-Sowell, A. R. (2010). The psychological sting of stigma: The costs of attributing ostracism to racism. Journal of Experimental Social Psychology, 46, 612-618.

Hales, A. H., Wesselmann, E. D., \& Williams, K. D. (2016). Prayer, self-affirmation, and distraction improve recovery from short-term ostracism. Journal of Experimental Social Psychology, 64, 8-20.

Hartig, T., Evans, G. W., Jamner, L. D., Davis, D. S., \& G€arling, T. (2003). Tracking restoration in natural and urban field settings. Journal of Environmental Psychology, 23, 109-123.

Hermann, A. D., Skulborstad H. M., \& Wirth, J. H. (2014). Inoculating against the aversive effects of ostracism with acceptance: The role of attachment styles. Social Influence, $9,255-271$.

Horton, D., \& Wohl, R. (1956). Mass communication and parasocial interaction. Psychiatry: Journal for the Study of Interpersonal Process, 19, 215-229.

Howell, A. J., Dopko, R. L., Passmore, H., \& Buro, K. (2011). Nature connectedness: Associations with well-being and mindfulness. Personality and Individual Differences, 51, 166-171.

Howell, A. J., Passmore, H., \& Buro, K. (2013). Meaning in nature: Meaning in life as a mediator of the relationship between nature connectedness and well-being. Journal of Happiness Studies, 14, 1681-1696.

Kashdan, T. B., \& Nezlek, J. B. (2012). Whether, when, and how is spirituality related to well-being? Moving beyond single occasion questionnaires to understanding daily process. Personality and Social Psychology Bulletin, 38, 1523-1535. 
Keltner, D., Gruenfeld, D. H., \& Anderson, C. A. (2003). Power, approach, and inhibition. Psychological Review, 110, 265-284.

Kirkpatrick, L. A. (1998). God as a substitute attachment figure: A longitudinal study of adult attachment style and religious change in college students. Personality and Social Psychology Bulletin, 24, 961-973.

Knausenberger, J., Hellmann, J. H., \& Echterhoff, G. (2015). When virtual contact is all you need: Subtle reminders of Facebook preempt social-contact restoration after exclusion. European Journal of Social Psychology, 45, 279-284.

Knowles, M. L. (2007). The nature of parasocial relationships (Unpublished doctoral dissertation). Northwestern University, Evanston, IL.

Knowles, M. L. (2013). Belonging regulation through the use of (para)social surrogates. In C. N. DeWall (Ed.), The Oxford handbook of social exclusion (pp. 275-285). New York, NY: Oxford University Press.

Knowles, M. L., \& Gardner, W. L. (2008). Benefits of membership: The activation and amplification of group identities in response to social rejection. Personality and Social Psychology Bulletin, 34, 1200-1213.

Knowles, M. L., Haycock, N., \& Shaikh, I. (2015). Does Facebook magnify or mitigate threats to belonging? Social Psychology, 6, 313-324.

Kruglanski, A. W., \& Mackie, D. M. (1990). Majority and minority influence: A judgmental process analysis. In W. Stroebe \& M. Hewstone (Eds.), European review of social psychology (Vol. 1, pp. 229-261). Chichester, UK: Wiley.

Kuehn, M. M., Chen, S., Gordon, A. M. (2015). Having a thicker skin: Social power buffers the negative effects of social rejection. Social Psychological and Personality Science, $6,701-709$. 
Langner, C. A., \& Keltner, D. (2008). Social power and emotional experience: Actor and partner effects within dyadic interactions. Journal of Experimental Social Psychology, $44,848-856$.

Laurin, K., Schumann, K., \& Holmes, J. G. (2014). A relationship with God? Connecting with the divine to assuage fears of interpersonal rejection. Social Psychological and Personality Science, 5, 777-785,

Leary, M. R., \& Baumeister, R. F. (2000). The nature and function of self-esteem: Sociometer theory. In M. P. Zanna (Ed.), Advances in experimental social psychology (Vol. 32, pp. 1-62). San Diego, CA: Academic Press.

Leary, M. R., Kelly, K. M., Cottrell, C. M., \& Schreindorfer, L. S. (2013). Construct validity of the need to belong scale: Mapping the nomological network. Journal of Personality Assessment, 95, 610-624.

Leary, M. R., Tambor, E. S., Terdal, S. K., \& Downs, D. L. (1995). Self-esteem as an interpersonal monitor: The sociometer hypothesis. Journal of Personality and Social Psychology, 68, 518-530.

Lelieveld, G., Moor, B., Crone, E. A., Karremans, J. C., \& van Beest, I. (2013). A penny for your pain? The financial compensation of social pain after exclusion. Social Psychological and Personality Science, 4, 206-214.

Lieberman, J. D., Solomon, S., Greenberg, J., \& McGregor, H. A. (1999). A hot new way to measure aggression: Hot sauce allocation. Aggressive Behavior, 25, 331-348.

Lücken, M., \& Simon, B. (2005). Cognitive and affective experiences of minority and majority members: The role of group size, status, and power. Journal of Experimental Social Psychology, 41, 396-413.

Maner, J. K., DeWall, C., Baumeister, R. F., \& Schaller, M. (2007). Does social exclusion motivate interpersonal reconnection? Resolving the 'porcupine problem.' Journal of Personality and Social Psychology, 92, 42-55. 
Mayer, F. S., \& Frantz, C. M. (2004). The connectedness to nature scale: A measure of individuals' feeling in community with nature. Journal of Environmental Psychology, 24, 503-515.

McConnell, A. R., Brown, C. M., Shoda, T. M., Stayton, L. E., \& Martin, C. E. (2011). Friends with benefits: On the positive consequences of pet ownership. Journal of Personality and Social Psychology, 101, 1239-1252.

McCourt, A., \& Fitzpatrick, J. (2001). The role of personal characteristics and romantic characteristics in parasocial relationships: A pilot study. Journal of Mundane Behavior, 2, 1-12.

Mead, N. L., Baumeister, R. F., Stillman, T. F., Rawn, C. D., \& Vohs, K. D. (2011). Social exclusion causes people to spend and consume strategically in the service of affiliation. Journal of Consumer Research, 37, 902-919.

Moscovici, S. (1980). Toward a theory of conversion behavior. In L. Berkowitz (Ed.), Advances in experimental social psychology (Vol. 13, pp. 209-239). New York, NY: Academic Press.

Norenzayan, A., \& Hansen, I. G. (2006). Belief in supernatural agents in the face of death. Personality and Social Psychology Bulletin, 32, 174-187.

Park, L. E., \& Maner, J. K. (2009). Does self-threat promote social connection? The role of self-esteem and contingencies of self-worth. Journal of Personality and Social Psychology, 96, 203-217.

Poon, K. T., Teng, F., Chow, J. T., \& Chen, Z. (2015). Desiring to connect to nature: Ostracism increases ecological behavior. Journal of Environmental Psychology, 42, $116-122$.

Ren, D., Wesselmann, E. D., \& Williams, K. D. (2013). Interdependent self-construal moderates coping with (but not the initial pain of) ostracism. Asian Journal of Social Psychology, 16, 320-326. 
Rubin, A. M., Perse, E. M., \& Powell, R. A. (1985). Loneliness, parasocial interaction, and local news viewing. Human Communication Research, 12, 155-180.

Rudert, S. C., \& Greifeneder, R. (2016). When it's okay that I don't play: Social norms and the situated construal of social exclusion. Personality and Social Psychology Bulletin, $42,955-969$.

Sachdev, I., \& Bourhis, R. Y. (1984). Minimal majorities and minorities. European Journal of Social Psychology, 14, 35-52.

Sachdev, I., \& Bourhis, R. Y. (1991). Power and status differentials in minority and majority group relations. European Journal of Social Psychology, 21, 1-24.

Schoel, C., Eck, J., \& Greifeneder, R. (2014). A matter of vertical position: Consequences of ostracism differ for those above versus below its perpetrators. Social Psychological and Personality Science, 5, 149-157.

Schoel, C., Zimmer, K., \& Stahlberg, D. (2015). The Spatial Power Motivation Scale - A semi-implicit measure of situational power motivation. Journal of Personality Assessment, 97, 66-80.

Schubert, T. W. (2005). Your highness: Vertical positions as perceptual symbols of power. Journal of Personality and Social Psychology, 89, 1-21.

Smith, A., \& Williams, K. D. (2004). R U There? Effects of ostracism by cell phone messages. Group Dynamics: Theory, Research, and Practice, 8, 291-301.

Teng. F., \& Chen, Z. (2012). Does social support reduce distress caused by ostracism? It depends on the level of one's self-esteem. Journal of Experimental Social Psychology, $48,1192-1195$.

Troisi, J. D., \& Gabriel, S. (2011). Chicken soup really is good for the soul: "Comfort food" fulfills the need to belong. Psychological Science, 22, 747-753. 
Twenge, J. M., Baumeister, R. F., Tice, D. M., \& Stucke, T. S. (2001). If you can't join them, beat them: Effects of social exclusion on aggressive behavior. Journal of Personality and Social Psychology, 81, 1058-1069.

Twenge, J. M., Zhang, L., Catanese, K. R., Dolan-Pascoe, B., Lyche, L. F., \& Baumeister, R. F. (2007). Replenishing connectedness: Reminders of social activity reduce aggression after social exclusion. The British Journal of Social Psychology, 46, 20-224.

Ulrich, R. S., Simons, R., Losito, B. D., Fiorito, E., Miles, M. A., \& Zelson, M. (1991). Stress recovery during exposure to natural and urban environments. Journal of Environmental Psychology, 11, 201-230.

Van Beest. I., Carter-Sowell, A. R., van Dijk, E., \& Williams, K. D. (2012). Groups being ostracized by groups: Is the pain shared, is recovery quicker, and are groups more likely to be aggressive? Group Dynamic: Theory, Research, and Practice, 16, 241254.

Van Beest, I., \& Williams, K. D. (2006). When inclusion costs and ostracism pays, ostracism still hurts. Journal of Personality and Social Psychology, 91, 918-928.

Vohs, K. D., Mead, N. L., \& Goode, M. R. (2006). Psychological consequences of money, Science, 314, 1154-1156.

Warburton, W. A., Williams, K. D., \& Cairns, D. R. (2006). When ostracism leads to aggression: The moderating effects of control deprivation. Journal of Experimental Social Psychology, 42, 213-220.

Wesselmann, E. D., \& Williams, K. D. (2010). The potential balm of religion and spirituality for recovering from ostracism. Journal of Management, Spirituality, and Religion, 7, $29-45$.

Williams, K. D. (2007). Ostracism. Annual Review of Psychology, 58, 425-452. 
Williams, K. D. (2009). Ostracism: A temporal need-threat model. In M. P. Zanna (Ed.), Advances in experimental social psychology (Vol. 41, pp. 275-314). San Diego, CA: Elsevier Academic Press.

Williams, K. D., Cheung, C. K. T., \& Choi, W. (2000). Cyberostracism: Effects of being ignored over the Internet. Journal of Personality and Social Psychology, 79, 748-762.

WIN/Gallup International (2015). Losing our religion? Two thirds of people still claim to be religious. Retrieved from http://www.wingia.com/en/news/losing_our_religion_two_thirds_of_people_still_clai m_to_be_religious/290/

Wirth, J. H., Sacco, D. F., Hugenberg, K., \& Williams, K. D. (2010). Eye gaze as relational evaluation: Averted eye gaze leads to feelings of ostracism and relational devaluation. Personality and Social Psychology Bulletin, 36, 869-882.

Wirth, J. H., \& Williams, K. D. (2009). “They don’t like our kind”: Consequences of being ostracized while possessing a group membership. Group Processes and Intergroup Relations, 12, 111-127.

Wojciszke, B., \& Struzynska-Kujalowicz, A. (2007). Power influences self-esteem. Social Cognition, 25, 472-494.

Zadro., L., Boland, C., \& Richardson, R. (2006). How long does it last? The persistence of the effects of ostracism in the socially anxious. Journal of Experimental Social Psychology, 42, 692-697.

Zadro, L., Williams, K. D., \& Richardson, R. (2004). How low can you go? Ostracism by a computer lowers belonging, control, self-esteem, and meaningful existence. Journal of Experimental Social Psychology, 40, 560-567. 
Zhou, X., \& Gao, D.-G. (2008). Social support and money as pain management mechanisms. Psychological Inquiry, 19, 127-144.

Zhou, X., Vohs, K. D., \& Baumeister, R. F. (2009). The symbolic power of money:

Reminders of money after social distress and physical pain. Psychological Science, 20, $700-706$. 


\section{Footnote}

${ }^{1}$ Please note that in Twenge et al.'s (2007) study participants thought of their favorite celebrity and not just any likeable celebrity as in the study reported by Gardner et al. (2005; see above). However, also a bond with the favorite celebrity is usually only parasocial, that is, it is an illusion of a face-to-face relationship with a media figure (Horton \& Wohl, 1956). This coping strategy is elaborated on in the section on social surrogates. 